\title{
Duration of hemodialysis associated with cardio-respiratory dysfunction and breathlessness: a multicenter study
}

\author{
Kornanong Yuenyongchaiwat ${ }^{\text {Corresp., } 1,2}$, Phatsara Vasinsarunkul ${ }^{1}$, Phoomipat Phongsukree ${ }^{1}$, Kodchaphan \\ Chaturattanachaiyaporn ${ }^{1}$, Opas Tritanon ${ }^{3}$ \\ 1 Physiotherapy Department, Faculty of Allied Health Sciences, Thammasat University, Pathumtani, Thailand \\ 2 Thammasat University Research Unit in Physical therapy in respiratory and cardiovascular systems, Thammasat University, Pathumthani, Thailand \\ 3 Division of Nephrology, Department of Internal medicine, Faculty of Medicine, Thammasat University, Pathumtani, Thailand \\ Corresponding Author: Kornanong Yuenyongchaiwat \\ Email address: ykornano@tu.ac.th
}

Background. Patients with hemodialysis suffer with protein-energy wasting and uremic myopathy lead to lack of physical activity and poor functional performance. However, ventilation abnormality in patients undergone hemodialysis remains controversial regarding the respiratory impairment. Therefore, the study aimed to determine the effect of duration of dialysis on respiratory function. Methods: A multicenter study with crosssectional study was designed in four hemodialysis outpatient clinics. Respiratory muscle strength (i.e., maximal inspiratory pressure (MIP) and maximal expiratory pressure (MEP)) pulmonary function test (i.e., forced vital capacity (FVC), forced expiratory volume in one second $\left(\mathrm{FEV}_{1}\right)$ and $\mathrm{FEV}_{1} / \mathrm{FVC}$ ratio), functional capacity (6-minute walk test) and sensation of breathlessness were assessed prior to dialysis. Results: A total of 100 hemodialysis patients were recruited with 38 females and 62 males. An average of duration of hemodialysis was $5.93 \pm 4.96$ years. Decreased MIP values, FEV $_{1}$ values, FVC values, $\% F_{1}$ and \%FVC were noted in patients with long duration of dialysis (defined as $\geq 5$ years of dialysis) compared to those with short duration of dialysis $\left(p_{s}<.05\right)$. In addition, increased sensation of breathlessness was observed in patients with long duration of dialysis $(p<.05)$. Furthermore, participants with long duration of dialysis had an increased risk of ventilatory restriction (OR 6.093, $p=.007$ ). 


\title{
Duration of hemodialysis associated with cardio- respiratory dysfunction and breathlessness: a multicenter study
}

\author{
Authors' names and institutional affiliations; \\ Kornanong Yuenyongchaiwat*1,2, Ph.D., Phatsara Vasinsarunkul ${ }^{1}$. B.Sc. Phoomipat \\ Phongsukree$^{1}$., B.Sc. Kodchaphan Chaturattanachaiyaporn ${ }^{1}$, B.Sc. Opas Tritanon, M.D. ${ }^{3}$ \\ ${ }^{1}$ Physiotherapy Department, Faculty of Allied Health Sciences, Thammasat University, Thailand \\ 2 Thammasat University Research Unit in Physical therapy in respiratory and cardiovascular \\ systems, Thailand. \\ 3. Division of Nephrology, Department of Internal medicine, Faculty of Medicine, Thammasat \\ University, Thailand

\section{Corresponding author:} \\ Assoc. Prof. Kornanong Yuenyongchaiwat, Ph.D. \\ ${ }^{1}$ Physiotherapy Department, Faculty of Allied Health Sciences, Thammasat University, \\ 99 Moo 18, Paholyothin Road, Klong Luang, Rangsit, Pathumthani, 12120, Thailand. \\ Tel +66 (0)29869213, E-mail: ykornano@tu.ac.th \\ 2 Thammasat University Research Unit in Physical therapy in respiratory and cardiovascular \\ systems, Pathumthani, Thailand.
}




\section{Abstract}

27

28

29

30

31

32

Background. Patients with hemodialysis suffer with protein-energy wasting and uremic myopathy lead to lack of physical activity and poor functional performance. However, ventilation abnormality in patients undergone hemodialysis remains controversial regarding the respiratory impairment. Therefore, the study aimed to determine the effect of duration of dialysis on respiratory function.

Methods: A multicenter study with cross-sectional study was designed in four hemodialysis outpatient clinics. Respiratory muscle strength (i.e., maximal inspiratory pressure (MIP) and maximal expiratory pressure (MEP)) pulmonary function test (i.e., forced vital capacity (FVC), forced expiratory volume in one second $\left(\mathrm{FEV}_{1}\right)$ and $\mathrm{FEV}_{1} / \mathrm{FVC}$ ratio), functional capacity (6minute walk test) and sensation of breathlessness were assessed prior to dialysis.

Results: A total of 100 hemodialysis patients were recruited with 38 females and 62 males. An average of duration of hemodialysis was $5.93 \pm 4.96$ years. Decreased MIP values, $\mathrm{FEV}_{1}$ values, $\mathrm{FVC}$ values, $\% \mathrm{FEV}_{1}$ and $\% \mathrm{FVC}$ were noted in patients with long duration of dialysis (defined as $\geq 5$ years of dialysis) compared to those with short duration of dialysis $\left(\mathrm{p}_{\mathrm{s}}<.05\right)$. In addition, increased sensation of breathlessness was observed in patients with long duration of dialysis $(\mathrm{p}<.05)$. Furthermore, participants with long duration of dialysis had an increased risk of ventilatory restriction (OR 6.093, $p=.007)$.

Keywords: chronic renal failure; hemodialysis; pulmonary function; respiratory muscle strength; restrictive pulmonary impairment; breathlessness; functional capacity 
49

50

51

52

53

54

55

56

57

58

59

60

61

62

63

64

65

66

67

68

69

70

71

72

73

74

75

76

77

78

79

80

81

82

83

84

85

86

87

88

89

90

91

92

93

\section{Introduction}

Chronic renal failure (CRF) is not only impact on loss of renal function, it has been also presented in cardiorespiratory problems including shortness of breathing. The effect of muscle wasting and uremia in patients with $\mathrm{CRF}$ who are on hemodialysis resulting in the respiratory and peripheral muscle weakness due to impair oxygen uptake, consumption, transportation and decrease in protein synthesis (Bark et al., 1988). Pulmonary complication is one of the major problems in patients with CRF that is because of fluid overload, pulmonary calcification and fibrosis and pulmonary edema (Craddock et al, 1977). In addition, inflammation process and protein-energy wasting contributed to cardiovascular disease and these may develop pulmonary impairment in uremic patients (Yoon, Choi \& Yun, 2009). A retrospective longitudinal study in Korea found that impairment of pulmonary function was associated with increase in the development of CRF (Kim et al., 2018). The prevalence of obstructive pulmonary function increased across GFR from 6\% in GER-2 to 11\% in GER-5 (Mukai et al., 2018). Compared to healthy individuals, patients with CRF shown decreased respiratory muscle strength and lung function (Bark et al., 1988; Karacan et al., 2006). Besides, a restrictive lung disease was found $36 \%$ of CRF patients with GFR $<15 \mathrm{~L} / \mathrm{min} / 1.73 \mathrm{~m}^{2}$ which markedly higher as GFR declined (Murtagh et al., 2007). Previous study reported the prevalence of lung dysfunction was related to declining glomerular filtration rate (GFR) and the prevalence of dyspnea symptom was 35\% among patients with end-stage renal disease (Murtagh et al., 2007). In addition, patients with CRF receiving hemodialysis or patients with end stage renal disease (i.e., a GFR below 15 $\mathrm{ml} / \mathrm{min} / 1.73 \mathrm{~m}^{2}$ ) are associated with high prevalence of cardiovascular disease e.g., hemodynamic stress, myocardial stress and injury (Ahmadmehrabi \& Wilson Tang, 2018). Therefore, patients treated with hemodialysis are related to the risk of poor cardio-respiratory function. However, results of the relationships CRF patients and cardio-respiratory performance are quite inconsistent, with some suggesting obstructive and other restrictive pulmonary impairment in CRF. It might be differences in sample size, and participants may account for such differences. Therefore, the present study aimed to explore the relationships between cardiorespiratory performance in end stage renal failure patients undergoing hemodialysis.

\section{Materials \& Methods}

The study was approved from the Ethics Human committee of Thammasat University, based on Declaration of Helsinki, the Belmont report, CIOMS guidelines, and the International practice (ICH-GCP) COA No. 334/2560, and also the Ethics in Human Research Committee of the Thammasat Hospital Medicine. All participants were informed and gave written consent prior to the study. A total of 100 patients with end stage renal disease on hemodialysis were recruited in four hemodialysis centers. Those underwent hemodialysis at least 3 times per weeks and more than 3 months. Participants aged between 30-75 years old both males and females were recruited. Individuals who had history of no-smoking or non-current smoker or ex-smoker are included. A current smoker is defined as at least one cigarette per day within 1 week and ex-smoker is defined as participants who had ceased cigarette smoking in 6 months ago prior to the test (Thornton, Lee \& Fry, 1994). The participant who had neurological problems (e.g., stroke), chronic cardio-respiratory disease (e.g., chronic cough, obstructive sleep apnea, history of chronic obstructive pulmonary disease or restrictive pulmonary disease, chronic heart failure), mental health problems, uncontrollable blood pressure (e.g., resting systolic blood pressure over $200 \mathrm{mmHg}$ or resting diastolic blood pressure more than $120 \mathrm{mmHg}$ ) were excluded. 
Pulmonary function tests (i.e., forced vital capacity: FVC, and forced expiratory volume in one second: $\mathrm{FEV}_{1}$ ) were assessed by the spirometeric meter (Carefusion MicroLab, United Kingdom) and a calibration was performed prior to the test. In addition, the respiratory muscle strength (inspiratory muscle and expiratory muscle strength) were assessed by respiratory pressure meter, which is a RPM01 (Micro Medical Ltd., United Kingdom). Individuals were asked to exhale slowly and completely and then inhale deeply and sustained pressure for $1.5 \mathrm{~s}$ to evaluate the maximal inspiratory pressure (MIP). Regarding to the maximal expiratory pressure (MEP), participants were instructed to exhale deeply and hold for $1.5 \mathrm{~s}$. these individuals performed 3-5 MIP and MEP maneuvers, with the highest two within $10 \mathrm{cmH}_{2} \mathrm{O}$ was recorded. These tests were followed by a recommendation of the American Thoracic Society/ European Respiratory Society (2002). Functional capacity is defined as 6-minute walk test (6MWT) and all individuals were asked to walk $30 \mathrm{~m}$ straight along a corridor in 6 minutes (American Thoracic Society, 2002). In addition, the participants were requested to rate the sensation of breathless during the past four weeks. Self-reported perceived breathlessness was measured using a numerical scale (1-5) with 1 corresponding to "very difficult to breath" and 5 corresponding to "not difficult to breath"; lower scores higher breathlessness. Furthermore, all participants were required to performed these tests prior to underwent hemodialysis. The determination of pulmonary ventilation, an obstructive lung disease is defined as FEV1/FVC $<0.70$ and restrictive impairment is defined as $\mathrm{FEV}_{1} / \mathrm{FVC} \geq 0.70$, and $\% \mathrm{FVC}<80$ (Johnson \& Theurer, 2014).

Data were displayed as mean and standard deviation, percentage, as appropriate. Statistical significance was set as the level of $p<.05$. Normality was verified using the Komogorov Siminov Goodness of Fitness test A chi-square test was used to analyze differences between short and long duration of dialysis and type of respiratory function. Pearson correlation was conducted to determine whether the duration of hemodialysis was related to cardiorespiratory function and sensation of breathlessness. To examine association between these relationships after controlling for age and sex, partial correlation analysis was conducted. Comparisons between two groups by categorized dialysis duration (defined as $<5$ years and $\geq 5$ years) were assessed with unpaired t-test.

\section{Results}

The mean age of patients with end stage renal disease was $51.54 \pm 11.19$ years. A total of 100 participants with 38 females and 62 males completed pulmonary function test respiratory muscle strength testing and 6MWT. A mean duration of hemodialysis was $5.93 \pm 4.96$ years. According to categorise the lung function into three groups; normal, obstructive and restrictive lung impairment, the result revealed that only 17 individuals $(17.00 \%)$ were categorised as a normal pulmonary function, whereas 82 participants $(82.00 \%)$ were categorised as a restrictive ventilatory impairment, none of participants was defined as obstructive lung function. Table 1 displays the descriptive data of CRF patients.

Table 1 here

Bivariate correlations between duration of hemodialysis and pulmonary function, respiratory muscle strength tests and 6MWT were presented in table 2. Duration of hemodialysis was negatively associated with FVC values, $\mathrm{FEV}_{1}$ values, MIP values, $\% \mathrm{FVC}, \% \mathrm{FEV}_{1}, 6$ - 
140

141

142

143

144

145

146

147

148

149

150

151

152

153

154

155

156

157

158

159

160

161

162

163

164

165

166

167

168

169

170

171

172

173

174

175

176

177

178

179

180

181

182

183

184

minute walk distance (6MWD) and sensation of breathlessness $(p<.05)$. In addition, these relationships remained after adjusting for age and sex; individuals with long duration of hemodialysis still had a poor cardio-respiratory performance (i.e., pulmonary function, respiratory muscle strength and functional capacity) and high sensation of breathlessness.

\section{Table 2 here}

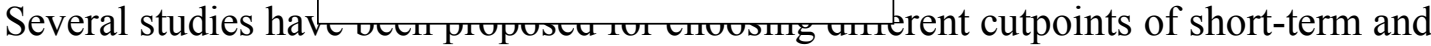
long-term duration of HD. For example, Hou et al. (2014) defined a long-term of HD as at least one year of HD. Another study defined as an average 51 months for the long period of HD treatment (Chazot et al., 2001). Here, the study is considering an equal number of the participants. Therefore, the categorization of period of hemodialysis is presented using cut point of five years. The study revealed that 50 out of $100(50.00 \%)$ of the CRF patients were categorized as long duration of dialysis ( $\geq 5$ years). Individuals with short duration of dialysis had higher FVC values, \%FVC, FEV 1 values, \% $\mathrm{FEV}_{1}$ MIP values and also lower sensation of breathlessness than those long duration of dialysis (see table 3). Individuals with long duration of hemodialysis (defined as a duration of hemodialysis $\geq 5$ years) had shorter duration of 6MWT than those with short duration of hemodialysis; however, these did not reach the conventional criterial ( $p>.05)$. Patients with CRF who had a long duration of hemodialysis had a high prevalence of restrictive pulmonary impairment at $47 \%(n=47)$ compared to individuals with short duration of dialysis $(3.00 \%, n=3)\left(\chi^{2}=8.575, p=.003\right)$.

Table 3 here

\section{Discussion}

The present study examined the relationship between duration of hemodialysis and cardio-respiratory performance in patients with CRF. The study found the association of MIP values, FVC values, predicted $\mathrm{FVC}, \mathrm{FEV}_{1}$ values, predicted $\mathrm{FEV}_{1}, 6 \mathrm{MWT}$ and the sensation of breathlessness. The study also shown that compared with short duration of hemodialysis (defined as $<5$ years), patients who had a long duration of hemodialysis displayed a reduction in of MIP values, FVC values, predicted $\mathrm{FVC}, \mathrm{FEV}_{1}$ values, predicted $\mathrm{FEV}_{1}, 6 \mathrm{MWT}$ and increased in the sensation of breathlessness.

The patients with hemodialysis in the study had low mean MIP values (60.92 \pm 28.55 $\mathrm{cmH}_{2} \mathrm{O}$ ); indicating inspiratory muscle weakness (defined as the ATS/ERS guideline which MIP values of $<80 \mathrm{cmH}_{2} \mathrm{O}$ ). Decreased respiratory muscle value was consistent with other studies (Bark et al., 1988; Fassbinder et al., 2015; Karacan et al., 2006). Karacan et al. (2006) reported inspiratory muscle was displayed $66.5 \pm 23.4 \mathrm{cmH}_{2} \mathrm{O}$ in 27 hemodialysis patients. In addition, Bark et al. found the MIP was $58.2 \pm 24.9 \mathrm{cmH}_{2} \mathrm{O}$ in 10 patients with CRF group (Bark et al., 1988). Therefore, the respiratory muscle strength weakness was noted in patients with CRF on hemodialysis. This might be due to uremic myopathy that leads to reduced strength in skeletal muscles and diaphragm (Tarasuik, Heimer, \& Bark, 1992). Tarasuik et al. (1992) reported that force and frequency of diaphragmatic muscle was decreased by $15 \%$ in the moderate uremia and by $45 \%$ in the severely uremic rats. In addition, they found the fatigability of diaphragm was increased in the moderately and severely uremic rats (Tarasuik et al., 1992). Therefore, muscle- 
185

related CRF complication may be explained by uremic myopathy which can be attributed structural changes (e.g., a decrease in excitability-contractility coupling of respiratory muscle) (Bark et al., 1988). Further, a deficit of vitamin D, anemia, hypophosphatemia, and malnutrition have been reported in patients with CRF (Karacan et al., 2006). One mechanism linking uremia to muscle weakness is altered active Calcium-transport of sarcoplasmic reticulum. Heimberg et al. found that the Calcium-transport system in uremic rabbits was changed; decrease in the calcium influx rate, increase in the calcium permeability and resulting decreased concentrating ability of sarcoplasmic reticulum (Heimberg et al., 1976). Those might be, at least in part, due to resulting in a reduction of respiratory muscle strength.

In the study, decrease in pulmonary function has been observed in patients receiving hemodialysis. Decreased spirometry parameters in patients undergoing hemodialysis was reported in several studies (Kovacevic et al., 2011; Kovelis et al., 2008). These CRF patients on hemodialysis showed a restrictive ventilatory defect (defined as $\mathrm{FVC}<80 \%$ and $\mathrm{FEV}_{1} / \mathrm{FVC} \geq$ 0.7 ) with have been similarly reported from the previous studies that is restrictive pulmonary impairment was common complication in patients with advanced CRF (Karacan et al., 2006; Kovelis et al., 2008). This is due to fluid overload, increasing interstitial oedema and bronchial wall decongestion resulting in decreased pulmonary function (Kovelis et al., 2008; Yilmaz et al., 2016). In addition, uremia has been reported to related pulmonary microcirculation dysfunction (Ewert et al., 2002). Another is that the decrease in pulmonary compliance of the thoracic wall that might be a muscle wasting with protein-energy wasting and inflammation (Mukai et al., 2018). Further, Bark et al. found that decreased respiratory muscle strength was related to a decrease in vital capacity among patients with CRF (Bark et al., 1988). Therefore, impaired respiratory muscles strength and poor ventilator capacity or lung restriction were noted in patients with end stage renal disease on hemodialysis. Previous studies have been reported that the relationships between lung function and inflammation were negatively associations (Bolton et al., 2011; Hancox et al., 2016). It is possible that a restrictive lung function may be in part, increased systematic inflammation. Therefore, cardio-pulmonary-renal interactions have been reported in CRF can cause a respiratory restriction, impaired gas exchange and also decreased exercise capacity (Husain-Syed et al., 2015). However, further studies need to explore the relationship with impaired cardiopulmonary function in CRF patients.

According to shortness of breathing, it was found that duration of hemodialysis was positively associated with breathlessness even after controlling for age and sex; longer duration of hemodialysis higher breathlessness in hemodialysis patients. The prevalence of dyspnea was also reported between $20 \%$ and $60 \%$. Palamidas et al. (2014) found that $100 \%$ of hemodialysis patients had displayed mild to moderated degree of chronic dyspnea (measured by Modified Medical Research Council Dyspnea Scale) before hemodialysis. However, it should be noted that only 25 hemodialysis patients were included in the study. In addition, Palamidas et al. assumed that an accumulation of excess lung water and pulmonary edema in patients with hemodialysis leads to premature airway closure and gas trapping. Further, a high ventilatory drive appealed before the hemodialysis which reflects increased respiratory effort and work of breathing (Palamidas et al., 2014) Therefore, impaired respiratory muscle and ventilatory impairment might be perceived as shortness of breathing from the hemodialysis patients.

The reduction in functional capacity determined by the 6MWT has been observed in several studies (Barril et al., 2018; Fassbinder et al., 2015). Fassbinder et al. found the distance of $6 \mathrm{MWT}$ was $418.67 \pm 117.3$ meters in 27 hemodialysis patients with an average age was $58.15 \pm 10.84$ years old (Fassbinder et al., 2015). Barril et al. (2018) found that the walking 
231

232

233

234

235

236

237

238

239

240

241

242

243

244

245

246

247

248

249

250

251

252

253

254

255

256

257

258

259

260

261

262

263

264

265

266

267

268

269

270

271

272

273

274

275

distance was $586.39 \pm 155$ meters in 108 patients with advanced chronic kidney disease, mean aged was $67.36 \pm 12.97$ years which was lower than the predicted values. Further, they reported the GFR was associated with the distance of 6MWT in patients with advanced chronic kidney disease (Barril et al., 2018). In the present study, the distance of 6MWT was 373.04 \pm 107.80 meters with a mean overall age of the participants was $51.54 \pm 11.19$ years and duration of hemodialysis was $5.93 \pm 4.96$ years. Thus, the impairment in functional capacity in the present study show a lower distance compared to the previous studies (Barril et al., 2018; Fassbinder et al., 2015). It has been already known that the demographic data such as age height, body weight and race are associated with distance of 6MWT (American Thoracic Society, 2002; Poh et al., 2006). In addition, the duration of hemodialysis might be in part of the walking distance in patients with CRF. Therefore, a prospective cohort study should be explored.

A number of limitation should be a consideration. A cross sectional study was designed which could not be a causal relationship. A confounding factors such as volume overload, laboratory analysis of renal function, and comorbidity was also not recorded. Other investigations such as laboratory investigation (e.g., arterial blood gas) or chest x-ray (e.g., interstitial lung disease) were not reported. In addition, all participants were only clinically stable; therefore, the results might not have generalized to CRF population as a whole. Finally, the sample size of the study was not calculated; however, the results of the study have reanalyzed with statistical power to detect the effect. According to a total number of 100 participants, the effect size for FVC values was 0.56 ; therefore, the retrospective statistical power was 0.79 for a 2-tailed alpha was 0.05 . Thus, the findings of study are commensurate adequate statistical power. However, the future study need to consider regarding the sample size calculation.

\section{Conclusions}

Patients with long duration of hemodialysis displayed a reduction of respiratory function, functional capacity and also increased breathlessness. In addition, these individuals shown a risk of restrictive ventilatory impairment.

\section{Acknowledgements}

The authors would like to thank all staff from hemodialysis Center at Thammasat University Hospital, Karunvej Hospital, Pat-Rangsit Hospital, and Phatara-Thonburi Hospital, for their kindly support and their helps. In addition, we would also like to thank the participants and their caregivers for participating in the study. Finally, the authors gratefully acknowledge the support provided by Thammasat University Research Unit in Physical Therapy in respiratory and cardiovascular systems. There is no conflict of interest in the study.

\section{References}

1. Ahmadmehrabi S, Wilson Tang WH. 2018. Hemodialysis-induced cardiovascular disease. Seminars in Dialysis 31(3):258-267. doi: 10.1111/sdi.12694

2. American Thoracic Society. 2002. ATS statement: guidelines for the six-minute walk test. American Journal of Respiratory and Critical Care Medicine 166:111-117.

3. American Thoracic Society/European Respiratory Society. 2002. ATS/ERS Statement on respiratory muscle testing. American Journal of Respiratory and Critical Care Medicine 166: 518-624. 
4. Bark H, Heimer D, Chaimovitz C Mostoslovski, M. 1988. Effect of chronic renal failure on respiratory muscle strength, Respiration 54:153-161.

5. Barril G, Nogueira A, Alvarez G, Sanchez-Tomero JA. 2018. Evaluation of functional capacity through the 6 minutes walking test (6MWT) in patients with CKD. Annals of Nutritional Disorders and Therapy 5(1):1053.

6. Bolton CE, Schumacher W, Cockcroft JR, Timpson NJ, Smith GD, Gallacher J, Rumley A, Lowe GD, Ebrahim S, Shale DJ, Ben-Shlomo Y. 2011. The CRP genotype, serum levels and lung function in men: The Caerphilly Prospective Study. Clinical Science 120(8): 347-355.

7. Chazot C, Laurent G, Charra B, Blanc C, VoVan C, Jean G, Vanel T, Terrat JC, Ruffet M. 2001. Malnutrition in long-term haemodialysis survivors. Nephrology Dialysis Transplantation 16(1): 61-69, https://doi.org/10.1093/ndt/16.1.61

8. Craddock PR, Fehr J, Dalmasso AP, Brigham KL, Jacob, HS. 1977. Hemodialysis leukopenia. Pulmonary vascular leukostasis resulting from complement activation by dialyzer cellophane membranes. Journal of Clinical Investigation 59: 878-888.

9. Ewert R, Opitz C, Wensel R, Dandel M, Mutze S, Reinke P. 2002. Abnormalities of pulmonary diffusion capacity in long-term survivors after kidney transplantation. Chest 122: 639-644.

10. Fassbinder TR, Winkelmann ER, Schneider J, Wendland J, Oliveira OB. 2015. Functional capacity and quality of life in patients with chronic kidney disease in predialytic treatment and on hemodialysis--A cross sectional study. Brazilian Journal of Nephrology 37(1): 47-54, doi: 10.5935/0101-2800.20150008.

11. Hancox RJ, Gray AR, Sears MR, Poulton, R. 2016. Systemic inflammation and lung function: A longitudinal analysis. Respiratory Medicine 111:54-59.

12. Heimberg KW, Matthews C, Ritz E, Augustin J, Hasselbach W. 1976. Active Ca transport of sacroplasmic reticulum during experimental uremia. Changes in kinetics and lipid composition. European Journal of Biochemistry 61(1):207-213.

13. Hou YC, Liu WC, Liao MT, Lu KC, Lo L, Pan HC, Wu CC, Hu OYP, Tang HS. 2014. Long-term and short-term effects of hemodialysis on liver function evaluated using the galactose single-point test. Scientific World Journal 2014:260939. doi: $10.1155 / 2014 / 260939$

14. Husain-Syed F, McCullough, PA, Birk, HW, Renker, M, Brocca, A, Seeger W, Ronco C. 2015. Cardio-Pulmonary-Renal Interactions: A Multidisciplinary Approach. Journal of the American College of Cardiology 65(22): 2433-2448. doi: 10.1016/j.jacc.2015.04.024.

15. Johnson JD, Theurer WM. 2014. A stepwise approach to the interpretation of pulmonary function tests. American Family Physician 89(5): 359-366.

16. Karacan O, Tutal E, Colak T, Sezer S, Eyübolu FO, Haberal, M. 2006. Pulmonary function in renal transplant recipients and end-stage renal disease patients undergoing maintenance dialysis. Transplantation Proceedings 38(2):396-400.

17. Kim SK, Bae JC, Baek JH, Hur KY, Lee MK, Kim, JH. 2018. Is decreased lung function associated with chronic kidney disease? A retrospective cohort study in Korea. BMJ Open 8: e018928, doi:10.1136/bmjopen-2017-018928

18. Kovacevic P, Stanetic M, Rajkovaca Z, Meyer FJ, Vukoja M. 2011. Changes in spirometry over time in uremic patients receiving long-term hemodialysis therapy. Pneumologia 60(1): 36-39. 
19. Kovelis D, Pitta F, Probst VS, Peres CP, Delfino VD, Mocelin AJ, Brunetto AF. 2008. Pulmonary function and respiratory muscle strength in chronic renal failure patients on hemodialysis. Brazilian Journal of Pulmonology 34(11):907-912.

20. Mukai H, Ming P, Lindholm B, Heimbürger O, Barany P, Anderstam B, Stenvinkel P, Qureshi AR. 2018. Restrictive lung disorder is common in patients with kidney failure and associates with protein-energy wasting, inflammation and cardiovascular disease. PLoS One 13(4):e0195585.

21. Murtagh FE, Addington-Hall J, Higginson IJ. 2007. The prevalence of symptoms in endstage renal disease: a systematic review. Advances in Chronic Kidney Disease 14(1): 8299.

22. Palamidas AF, Gennimata SA, Karakontaki F, Kaltsakas G, Papantoniou I, Koutsoukou A, Milic-Emili J, Vlahakos DV, Koulouris NG. 2014. Impact of hemodialysis on dyspnea and lung function in end stage kidney disease patients. BioMed Research International 2014. http://dx.doi.org/10.1155/2014/212751

23. Poh H, Eastwood PR, Cecins NM, Ho KT, Jenkins S. 2006. Six-minute walk distance in healthy Singaporean adults cannot be predicted using reference equations derived from Caucasian populations. Respiratory 11(2): 211-216.

24. Tarasuik A, Heimer D, Bark H. 1992. Effect of chronic renal failure on skeletal and diaphragmatic muscle contraction. American review of respiratory disease 146(6): 13831388.

25. Thornton A, Lee P, Fry J. Differences between smokers, ex-smokers, passive smokers and non-smokers. Journal of Clinical Epidemiology 1994;47(10):1143-1162.

26. Yilmaz S, Yildirim Y, Yilmaz Z, Kara AV, Taylan M, Demir M Coskunsel M, Kadiroglu AK, Yilmaz ME. 2016. Pulmonary function in patients with end-stage renal disease: effects of hemodialysis and fluid overload. Medical Science Monitor 22: 2779-2784.

27. Yoon SH, Choi NW, Yun, SR. 2009. Pulmonary dysfunction is possibly a marker of malnutrition and inflammation but not mortality in patients with end-stage renal disease. Nephron Clinical Practice 11(1): 1-6. 


\section{Table $\mathbf{1}$ (on next page)}

Table 1 Demographic and characteristics of chronic renal failure patients

Table 1 Demographic and characteristics of chronic renal failure patients 
1 Table 1 Demographic and characteristics of chronic renal failure patients

2

\begin{tabular}{|c|c|c|}
\hline & N (\%) & mean $\pm \mathrm{SD}$ \\
\hline Sex & & \\
\hline Female & $38(38.00)$ & \\
\hline Male & $62(62.00)$ & \\
\hline Age & & $51.54 \pm 11.19$ \\
\hline Duration of hemodialysis (yr) & & $5.93 \pm 4.96$ \\
\hline 6-MWD (meters) & & $373.04 \pm 107.80$ \\
\hline $\mathrm{MIP}\left(\mathrm{cmH}_{2} \mathrm{O}\right)$ & & $61.42 \pm 28.51$ \\
\hline $\mathrm{MEP}\left(\mathrm{cmH}_{2} \mathrm{O}\right)$ & & $67.64 \pm 30.23$ \\
\hline $\mathrm{FVC}(\mathrm{L})$ & & $2.09 \pm 0.74$ \\
\hline $\mathrm{FVC}(\%)$ & & $64.71 \pm 18.12$ \\
\hline FEV1(L) & & $1.94 \pm 0.67$ \\
\hline FEV1(\%) & & $71.03 \pm 20.87$ \\
\hline FEV1/FVC & & $94.12 \pm 5.84$ \\
\hline PEFR & & $273.94 \pm 122.66$ \\
\hline PEFR (\%) & & $58.68 \pm 23.05$ \\
\hline Sensation of breathlessness & & $3.76 \pm 1.15$ \\
\hline
\end{tabular}

$3 \mathrm{MIP}$; maximal inspiratory pressure, MEP; maximal expiratory pressure, FVC; forced vital capacity, $\mathrm{FEV} \mathrm{f}_{1}$; forced

4 expiratory volume in the first second, 6MWD; 6-minute walk distance

5

6

7 


\section{Table 2(on next page)}

Table 2 Correlation between duration of hemodialysis and respiratory function in chronic renal failure patients

Table 2 Correlation between duration of hemodialysis and respiratory function in chronic renal failure patients 
1 Table 2 Correlation between duration of hemodialysis and respiratory function in chronic renal

2 failure patients

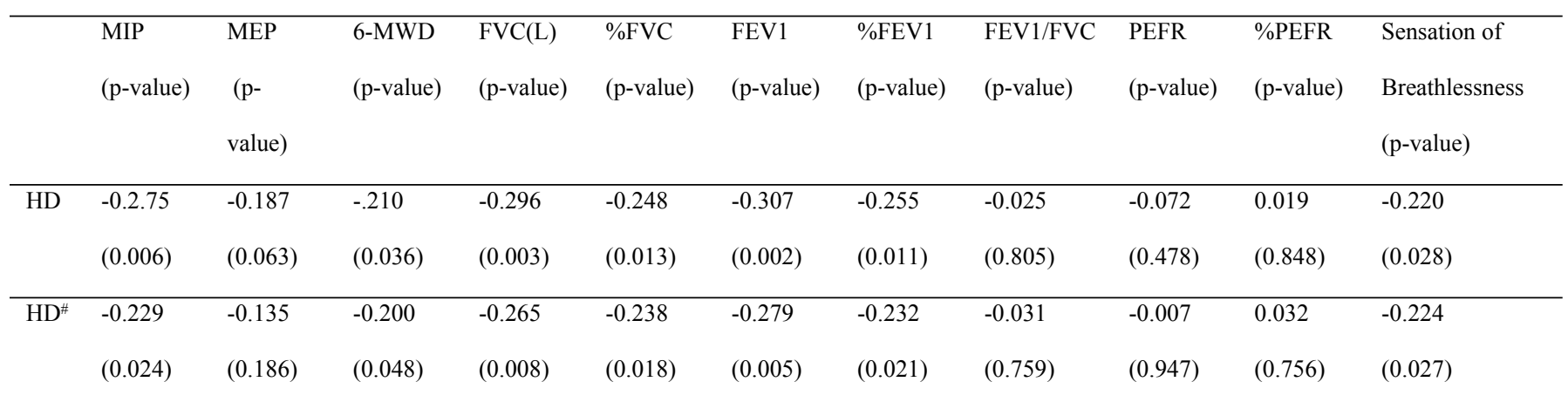

3 \# Controlling for age and sex

4 HD; hemodialysis, FVC; forced vital capacity, FEV1; forced expiratory volume in the first second, PEF; peak

5 expiratory flow, MIP; maximal inspiratory pressure, MEP; maximal expiratory pressure 


\section{Table 3 (on next page)}

Table 3 displays the differences in pulmonary function and respiratory muscle strength by categorized duration of hemodialysis

Table 3 displays the differences in pulmonary function and respiratory muscle strength by categorized duration of hemodialysis 
1 Table 3 displays the differences in pulmonary function and respiratory muscle strength by

2 categorized duration of hemodialysis

\begin{tabular}{|c|c|c|c|c|c|c|}
\hline & $\begin{array}{l}\text { Duration of HD }<5 y r s \\
\qquad(\mathrm{n}=50)\end{array}$ & $\begin{array}{l}\text { Duration of HD } \geq 5 \text { years } \\
\qquad(\mathrm{n}=50)\end{array}$ & $\mathrm{t}(98)$ & p-value & $95 \% \mathrm{CI}$ & $\begin{array}{l}\text { Effect size } \\
\text { Cohen's } d\end{array}$ \\
\hline $\mathrm{MIP}\left(\mathrm{cmH}_{2} \mathrm{O}\right)$ & $67.42 \pm 25.47$ & $55.42 \pm 30.33$ & 2.142 & 0.035 & 0.88 to 23.12 & 0.428 \\
\hline $\mathrm{MEP}\left(\mathrm{cmH}_{2} \mathrm{O}\right)$ & $71.10 \pm 25.93$ & $64.18 \pm 33.91$ & 1.146 & 0.254 & -5.06 to 18.90 & 0.229 \\
\hline 6-MWD (meters) & $386.14 \pm 122.29$ & $359.94 \pm 90.39$ & 1.218 & 0.226 & -16.48 to 68.88 & 0.244 \\
\hline FVC (L) & $2.29 \pm 0.74$ & $1.89 \pm 0.69$ & 2.777 & 0.007 & 0.11 to 0.68 & 0.559 \\
\hline $\mathrm{FVC}(\%)$ & $69.74 \pm 18.27$ & $59.68 \pm 16.68$ & 2.877 & 0.005 & 3.12 to 17.01 & 0.575 \\
\hline $\mathrm{FEV}_{1}(\mathrm{~L})$ & $2.12 \pm 0.66$ & $1.77 \pm 0.63$ & 2.706 & 0.008 & 0.09 to 0.60 & 0.542 \\
\hline $\mathrm{FEV}_{1}(\%)$ & $76.60 \pm 21.56$ & $65.46 \pm 18.74$ & 2.758 & 0.007 & 3.13 to 19.16 & 0.552 \\
\hline $\mathrm{FEV}_{1} / \mathrm{FVC}$ & $93.70 \pm 5.78$ & $94.54 \pm 5.93$ & -0.717 & 0.475 & -3.16 to 1.48 & 0.143 \\
\hline PEFR & $278.48 \pm 126.02$ & $269.40 \pm 120.31$ & 0.369 & 0.713 & -39.82 to 57.98 & 0.074 \\
\hline (\%) PEFR & $58.80 \pm 24.63$ & $58.57 \pm 21.60$ & 0.050 & 0.960 & -8.96 to 9.43 & 0.010 \\
\hline Sensation of breathlessness & $4.08 \pm 0.90$ & $3.44 \pm 1.28$ & 2.892 & 0.005 & 0.20 to 1.08 & 0.578 \\
\hline
\end{tabular}

3 HD; hemodialysis, MIP; maximal inspiratory pressure, MEP; maximal expiratory pressure, FVC; forced vital

4 capacity, $\mathrm{FEV}_{1}$; forced expiratory volume in the first second, $6 \mathrm{MWD}$; 6-minute walk distance

5

6

7

8 
